\title{
The use of a freeze-dried extract of Ligusticum mutellina in a cosmetic cream with potential antioxidant properties
}

\author{
Baj Tomasz ${ }^{1 *}$, Sieniawska Elwira ${ }^{1}$, Kubiak BartŁomiej ${ }^{2}$, Partyka Danuta ${ }^{2}$ \\ ${ }^{1}$ Department of Pharmacognosy with Medical Plant Unit, Medical University of Lublin, Poland \\ ${ }^{2}$ Department of Pharmaceutical Technology, Faculty of Pharmacy, Nicolaus Copernicus University in Toruń, Poland
}

\begin{tabular}{|c|c|}
\hline ARTICLE INFO & ABSTRACT \\
\hline $\begin{array}{l}\text { Received } 01 \text { September } 2016 \\
\text { Accepted } 26 \text { September } 2016\end{array}$ & \multirow{2}{*}{$\begin{array}{l}\text { The aim of this work was to develop a cream formulation with potential antioxidant } \\
\text { properties. Herein, a freeze-dried extract of Ligusticum mutellina was used as a source of } \\
\text { active compounds. The proposed qualitative composition of the cream was characterized } \\
\text { by a good polyphenolic compounds release profile. Of note, the highest } \mathrm{R}^{2} \text { adj values were } \\
\text { obtained for the Korsmeyer-Peppas and Higuchi models ( } 0.9159 \text { and } 0.9226 \text {, respectively). } \\
\text { These results indicate that a freeze-dried extract of } L \text {. mutellina, due to its retained high } \\
\text { phenolic acids content, could become a key component in antioxidant creams. }\end{array}$} \\
\hline $\begin{array}{l}\text { Keywords: } \\
\text { cosmetic formulation, } \\
\text { phenolic acids, } \\
\text { antioxidant properties. }\end{array}$ & \\
\hline
\end{tabular}

\section{INTRODUCTION}

In a majority of cosmetic creams, active plant substances are common ingredients that are responsible for several beneficial, multidirectional properties, among others, antioxidant, antibacterial, antifungal, anti-inflammatory or astringent activity [14,18,21-24]. This action is conditioned by the chemical composition of the plant substances used in the cosmetic. The most frequently listed group of natural protective compounds are phenolic acids. These occur in plants predominantly in a linked form as esters and glycosides, or as more complex lignans and hydrolysable tannins. Compounds derived from hydroxycinnamates often form ester linkage with carboxylic acids or glucose, and derivatives of hydroxybenzoic acids are usually present as glycosides [7]. Breinholt [3] described combinations of phenolic acids with the flavonoids. fatty acids and sterols present in the plant cells. Phenolic acids are biogenetically formed in plants from shikimic acid via the phenylpropanoid pathway, as well as through the degradation of lignin and cell wall polymers in vascular plants $[4,6]$.

The presented work is a continuation of earlier research on the phytochemical composition and activity of extracts from the L. mutellina herb, which showed interesting biological properties $[19,20]$.

The aim of this work was to develop a cream formulation with potential antioxidant properties containing a lyophilized extract of L. mutellina as an active ingredient.

\footnotetext{
* Corresponding author

e-mail: tbaj@pharmacognosy.org
}

\section{MATERIAL AND METHODS}

The herb of L. mutellina was collected in the botanical garden of the Department of Pharmacognosy, Medical Plant Unit, Medical University of Lublin, in September 2010. The herb was dried in the shade, pulverized and sieved $(0.5 \mathrm{~mm}$ sieve).

\section{Preparation of the extract from $L$. purpurea herb}

In this preparation, $300 \mathrm{~mL}$ of distilled water was added to the plant material $(100 \mathrm{~g})$ and the extract was produced via the heating basket under reflux for $2 \mathrm{~h}$. Subsequently, this was concentrated to a volume of $50 \mathrm{~mL}$ under reduced pressure on a rotary evaporator and subjected to freezedrying (Freeze Dryer, Christ Alpha 2-4 LD, Germany).

\section{Preparation of cream containing the lyophilized extract}

$85.0 \mathrm{~g}$ of cholesterol ointment was mixed with $5.0 \mathrm{~g}$ of lyophilisate, $5.0 \mathrm{~g}$ of Miglyol 812 and $5.0 \mathrm{~g}$ of cis-oleic acid. The ingredients were transferred into a container and were stirred in the automatic mixer (Unguator 2100, Gako, Germany) for 2 minutes at a speed of stirrer 5. The choice of a cholesterol ointment as a cream base was justified by the nature of the active substances present in the extract of L. mutellina. Due to the hydrophilic properties of the dominant component, chlorogenic acid $(\log \mathrm{P}=0.6)$, it was not possible to utilize bases containing a large amount of water (hydrogels, o/w emulsion), as these would not enable a release and penetration of active substances into the stratum corneum of the skin. What is more, an emulsion base was rejected during preliminary tests due to its limited stability. In our work, Oleic acid and Miglyol were added to improve the lubricating properties of the ointment. Doing this also 
achieved the effect of promoting absorption (oleic acid). While some antioxidants are usually included within such formulations so as to inhibit the degradation of the active substances, in this study, this was not done, as their addition would cause overestimation of the results obtained using F-C reagent.

\section{Permeation studies}

The assessment of pharmaceutical availability of ointment polyphenols was performed in a chamber Enhancer cell - a six-position apparatus with a paddle attachment. The agitator speed was 50 revolutions $/ \mathrm{min}$, the chamber extraction surface was $400 \mathrm{~mm}^{2}$ and measurements were carried out at $40 \pm 0.5^{\circ} \mathrm{C}$ (the temperature of the acceptor fluid). In doing this, $1 \mathrm{~g}$ of ointment was weighed and placed in the cell, then the ointment was covered with a Cuprophan membrane (previously exposed to distilled water for $24 \mathrm{~h}$ ). The cells were then placed in a beaker containing $100 \mathrm{~mL}$ of the acceptor fluid (1.6\% SLS - sodium lauryl sulfate).

\section{Determination of the sum of phenolic compounds in the liquid acceptor}

For the sum of phenolic compounds determination, $1 \mathrm{~mL}$ of acceptor solution was taken at appropriate time intervals. In so-doing, $1 \mathrm{~mL}$ of acceptor solution was mixed with $0.5 \mathrm{~mL}$ of Folin-Ciocaltou reagent (diluted $10 \times$ with distilled water). After 5 minutes, $0.5 \mathrm{~mL}$ of sodium bicarbonate was added and the mixture was left for 30 minutes in the dark. Absorbance was measured in the presence of water at $\lambda=$ $735 \mathrm{~nm}$.

To generate the calibration curve, $2 \mathrm{mg}$ of chlorogenic acid was exactly weighed and dissolved in $2 \mathrm{~mL}$ of methanol (basic solution). The prepared dilutions were in a range of $0.86-4.23 \mathrm{mg} / \mathrm{mL}$. The concentration of phenolic compounds in the liquid acceptor was calculated by using the equation: Abs $=0.07840 \times$ conc -0.04815 .

\section{Statistical analysis}

The obtained results were used to determine the most appropriate kinetic model describing the process of release. For this purpose a free app for MS Excel - DDSolver was used [27].

\section{RESULTS AND DISCUSSION}

Following $24 \mathrm{~h}$, approx. $12 \%$ of the contained polyphenols were released as chlorogenic acid. Table 1 and Figure 1 present the release kinetics of active compounds from ointment. Moreover, the results of matching the kinetics

Table 1. The results of matching the kinetics of release to the individual models

\begin{tabular}{|l|c|}
\hline \multicolumn{1}{|c|}{ Dissolution Data Modeling } & Rsqr_adj \\
\hline Peppas-Sahlin Model & 0.8556 \\
\hline Hixson-Crowell Model & 0.7414 \\
\hline Korsmeyer-Peppas Model & 0.9159 \\
\hline Higuchi Model & 0.9226 \\
\hline First-order Model & 0.7503 \\
\hline Zero-order Model & 0.7225 \\
\hline
\end{tabular}

of release to the individual models are shown in Table 1. The best match was obtained by way of the Higuchi model (highest $\mathrm{R}^{2} \mathrm{adj}$ ), which either describes the release from semisolid formulations or it describes formulations with a modified release [5]. Initially, the Higuchi model referred to the release of planar systems [9] but was extended to a system with different shapes and pore types [8]. This model is based on the assumption that an initial concentration in the matrix is much higher than its solubility, diffusion occurs only in one direction, the particles of the substance are much smaller than the thickness of the system, soaking of the system and its dissolution practically do not occur, the diffusivity of the system is unchanging and the condition of immersion in the environment of acceptor is kept. The Higuchi model relating to the semisolid formulations is described by the equation:

$$
f_{t}=Q=A \sqrt{D\left(2 C-C_{s}\right) C_{s} t},
$$

where, $\mathrm{Q}$ is the amount of substance released at time t per unit area $\mathrm{A}, \mathrm{C}$ is the initial concentration of the substance, $\mathrm{C}_{\mathrm{s}}$ is the solubility of the substance in the base, and D is the diffusivity of the molecules (diffusion coefficient) in the base. This relationship is valid for the entire release time, until exhaustion of reservoir analyte.

The simplified Higuchi model [9] is described by the equation:

$$
f_{t}=Q=K_{H} t^{1 / 2}
$$

where, $\mathrm{K}_{\mathrm{H}}$ is a Higuchi constant decomposition [1].

Compounds of plant origin with antioxidative properties possess the ability to inhibit certain enzymes, "capture" the singlet oxygen, degrade peroxides and also to support other antioxidants [12]. Chlorogenic acid is among the more potent herbal antioxidants. Structurally, this is an ester of caffeic and quinic acid, and it is also an antiviral and an antibacterial agent [22] that is active against gram-positive bacteria (Staphylococcus aureus and Bacillus subtilis) and Gram-negative bacteria (Escherichia coli) [28]. In addition, it acts as an anti-allergic compound [10], modulates the activity of cytochrome P450 [26], exhibits antiviral properties against HIV [13] and demonstrates anti-tumor effects [25]. Furthermore, chlorogenic acid has no inhibitory effect

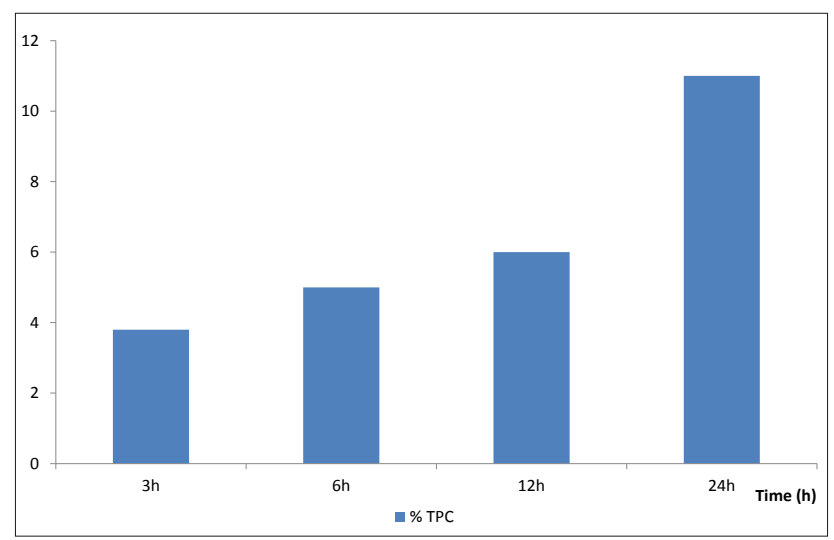

Figure 1. The release of the total phenolic compounds (TPC) from the cream during the 24 hours 
cell proliferation. This differentiates chlorogenic acid from the other broad spectrum MMP inhibitors such as batimastat (BB-94) [15,17]. Kono et al. [11] reported that the antioxidant properties of chlorogenic acid are linked to the catechol structure of the phenyl ring. The double bond adjacent to the catechol unit also provides a place holder for the free radicals. Chlorogenic acid also strongly inhibits zinc-dependent metalloproteinases of the intercellular matrix. Metalloproteinases (MMPs) are involved in the cleavage of surface receptors and the release of apoptotic ligands, as well as in the activation and deactivation of chemokines and cytokines. Moreover, metalloproteinases play a very important role in cell reproduction, migration, differentiation, angiogenesis and apoptosis. Of the metalloproteinases, MMP-9 is involved in the degradation of type IV collagen, a major component of the extracellular matrix $[2,16]$. Chlorogenic acid has selective, dose-dependent activity towards MMP-9. Herein, the IC50 is in the range of 30-50 nM.

\section{CONCLUSION}

L. mutellina extract has a high content of polyphenols, and in our work, a freeze-dried extract was used to prepare a skin care cream composition having potential antioxidant properties. The proposed qualitative composition of the cream was characterized by it having a good polyphenolic compounds release profile. Indeed, all release profiles showed a high rate of $R^{2}$ adj. The highest $R^{2}$ adj value, however, was obtained via the Korsmeyer-Peppas and Higuchi models (0.9159 and 0.9226, respectively). These results indicate that a freeze-dried extract of L. mutellina retains a high content of phenolic acids, and that it may be utilized within certain antioxidant cream formulations.

\section{ACKNOWLEDGMENT}

These results of the work have been patented by the Polish Patent Office B1218726.

\section{REFERENCES}

1. Arhewoh I.M., Okhamafe A.O.: An overview of site-specific delivery of orally administered proteins/peptides and modeling considerations. JMBR, 3(1), 7-20, 2004.

2. Basset P., Okada A., Chenard M.P. et al.: Matrix metalloproteinases as stromal effectors of human carcinoma progression: therapeutic implications. Matrix Biol., 15, 535-541, 1997.

3. Breinholt V.: Desirable versus harmful levels of intake of flavonoids and phenolic acids. In: Natural antioxidants and anticarcinogens in nutrition. health and disease. J.T. Kumpulainen and J.T. Salonen. The Royal Society of Chemistry, 93-99, 1999.

4. Carpita N., McCann M.: The cell wall. In: Buchanan. et al., Biochemistry and molecular biology of plants. Rockville MD: American Society of Plant Physiologists, 52-108, 2000.

5. Costa P., Sousa Lobo J.M.: Modeling and comparison of dissolution profiles. Eur. J. Pharm. Sci., 13 (2), 123-133, 2001.

6. Croteau R., Kutchan T.M., Lewis N.G.: Natural products (secondary metabolites) In: Buchanan. et al., Biochemistry andmolecular biology of plants. Rockville MD: American Society of Plant Physiologists, 1250-1318, 2000.

7. Gawlik-Dziki U.: Fenolokwasy jako bioaktywne składniki żywności. Żywność. Nauka. Technologia. Jakość, 4, 29-40, 2004.
8. Grassi M., Grassi G.: Mathematical modeling and controlled drug delivery: matrix systems. Current Drug Delivery, 2(1), 97-116, 2005.

9. Higuchi T.: Mechanism of sustained-action medication: theoretical analysis of rate of release of solid drugs dispersed in solid matrices. J. Pharm. Sci., 52, 1145, 1963.

10. Ito H., Miyazaki T., Ono M., Sakurai H.: Antiallergic activities of rabdosiin and its related compounds: chemical and biochemical evaluations. Bioorg. Med. Chem., 6, 1051-1056, 1998.

11. Kono Y., Kobayashi K., Tagawa S. et al.: Antioxidant activity of polyphenolics in diets. Rate constants of reactions of chlorogenic acid and caffeic acid with reactive species of oxygen and nitrogen. Biochimica et Biophysica Acta, 1335(3), 335-342, 1997.

12. Larson R.A.: The antioxidants of higher plants. Phytochemi, 4, 969-978, 1988.

13. MacDougall J.R., Matrisian L.M.: Contributions of tumor and stromal matrix metalloproteinases to tumor progression. invasion and metastasis. Cancer Metastasis Reviews, 14, 351-362, 1995.

14. Mandal S.M., Chakraborty D., Dey S.: Phenolic acids act as signaling molecules in plant-microbe symbioses. Plant Signaling \& Behavior, 5, 359-368, 2010.

15. McDougall B., King P.J., Wu B.W. et al.: Dicaffeoylquinic and dicaffeoyltartaric acids are selective inhibitors of human immunodeficiency virus type 1 integrase. Antimicrob. Agents Chemother., 42, 140-146, 1998.

16. Nelson A.R., Fingleton B., Rothenberg M.L. et al: Matrix metalloproteinases: biologic activity and clinical implications. J. Clin. Oncol., 18, 1135-1149, 2000.

17. Nemunaitis J., Poole C., Primrose J. et al.: Combined analysis of studies of the effects of the matrix metalloproteinase inhibitor marimastat on serum tumor markers in advanced cancer: selection of a biologically active and tolerable dose for longer-term studies. Clinical Cancer Research, 4, 1101-1109, 1998.

18. Proestos C., Boziaris I.S., Nychas G-J.E., Komaitis M.: Analysis of flavonoids and phenolic acids in Greek aromatic plants: Investigation of their antioxidant capacity and antimicrobial activity. Food Chem., 95, 664-671, 2006.

19. Sieniawska E., Baj T., Dudka J., Gieroba R., Swiatek L., Rajtar B., Glowniak K., Polz-Dacewicz M.: Cytotoxicity. antioxidant activity and an effect on CYP3A4 and CYP2D6 of Mutellina purpurea L. extracts. Food Chem. Toxicol., 52, 188-192, $2013 \mathrm{~B}$.

20. Sieniawska E., Los R., Baj T., Malm A., Glowniak K.: Antimicrobial efficacy of Mutellina purpurea essential oil and alpha-pinene against Staphylococcus epidermidis grown in planktonic and biofilm cultures. Ind. Crops Prod., 51, 152-157, 2013A.

21. Skalicka-Woźniak K., Głowniak K.: Quantitative Analysis of Phenolic acids in extracts obtained from the ruits of Peucedanum alsaticum L. and Peucedanum cervaria (L.) Lap. Chromatographia. 68, 585-590, 2008.

22. Skalicka-Woźniak K., Los R., Glowniak K., Malm A.: Antimicrobial activity of fatty acids from fruits of Peucedanum cervaria and $P$. alsaticum. Chem Biodivesity, 7, 2748-2754, 2010.

23. Skalicka-Woźniak K., Los R., Glowniak K., Malm A.: Comparison of hydrodistillation and headspace solid-phase microextraction techniques for antibacterial volatile compounds from the fruits of Seseli libanotis. Nat. Prod. Commun., 5, 1427-1430, $2010 \mathrm{~B}$.

24. Tamagnone L., Merida A., Stacey N. et al.: Inhibition of phenolic acid metabolism results in precocious cell death and altered cell morphology in leaves of transgenic tobacco plants. Plant Cell, 10, 1801-1816, 1998.

25. Tanaka T., Nishikawa A., Shima H. et al.: Inhibitory effects of chlorogenic acid. reserpine. polyprenoic acid (E-5166). or coffee on hepatocarcinogenesis in rats and hamsters. Basic Life Sci., 52, 429-40, 1990.

26. Teel R.W., Huynh H.: Modulation by phytochemicals of cytochrome P450-linked enzyme activity. Cancer Lett., 133, 135-41, 1998.

27. Zhang. Y., Huo. M., Zhou. J. et al.: DDSolver: An add-in program for modeling and comparison of drug dissolution profiles AAPS J., 12 (3), 263-271, 2010

28. Zhao M., Wang H., Yang B., Tao H.: Identification of cyclodextrin inclusion complex of chlorogenic acid and its antimicrobial activity. Food Chem., 120, 1138-1142, 2010. 